\title{
Improvement of maize bread quality through modification of dough rheological properties by lactic acid bacteria fermentation
}

Adediwura T. Falade, M. Naushad Emmambux and John R.N. Taylor*

Institute for Food, Nutrition and Well-being and Department of Food Science, University of Pretoria, Private Bag X 20, Hatfield 0028, South Africa

*Corresponding Author: John R.N. Taylor

Phone: +27 124204296

Fax: +27 124202839

E-mail: john.taylor@up.ac.za

Keywords: Maize bread, Sourdough fermentation, Starch modification, Rheological properties

Abbreviations: $\tan \delta$, tan delta; cfu, colony forming units; CLSM, Confocal laser scanning microscopy; DSC, Differential scanning calorimetry. 


\begin{abstract}
This work investigated how sourdough fermentation improves maize bread quality. Maize sourdoughs were made by fermenting maize flour with multiple strains starter culture and with Lactobacillus plantarum. Sourdough fermentation of maize dough brought about a 25$26 \%$ increase in loaf volume of maize bread. Confocal laser scanning microscopy revealed a cohesive dough structure in the sourdoughs. Larger cells were also observed in maize breads with maize sourdough. Differential scanning calorimetry showed that maize sourdough had a slightly lower endothermic peak temperature and higher endothermic peak enthalpy than straight maize dough. Rheological analysis showed that maize sourdoughs had a shorter relaxation time. Strain sweep analysis suggested that maize sourdoughs had the lowest elastic modulus, all indicating a softer and less elastic dough. Temperature sweep analysis showed an initial less elastic dough and a final high tan delta, suggesting that the maize dough could withstand gas expansion pressure during baking without crumbling. It appears that improvement in maize bread quality by sourdough fermentation is primarily due to starch granule modification which makes the dough more cohesive, soft and less elastic and improves its ability to trap and withstand the pressure of the expanding carbon dioxide during fermentation and baking.
\end{abstract}




\section{Introduction}

Due to the high cost of wheat importation in countries where the climatic conditions do not favour its cultivation, for example tropical and sub-tropical Africa, alternative sources of bread making flour such as maize are required (reviewed by Goodall et al., 2012). According to FAOSTAT (2012), maize is by far the most important crop produced in Africa (about 69.6 million tons). However, the challenge is to produce bread from maize that will imitate closely the desirable qualities (high loaf volume and open crumb structure) that make wheat bread acceptable by consumers. Wheat gluten is the only protein with the proper functionality to produce high-quality breads (reviewed by Mejia et al., 2012). This is attributed to its unique property of forming strong viscoelastic dough when hydrated (reviewed by Goodall et al., 2012).

The use of maize in wheat-free and gluten-free breadmaking is not common. The few investigations have included additives such as egg and maize starch (Sanni et al., 1997), improver (S500 Acti-plus, Puratos) (Brites et al., 2010), soybean flour and ascorbic acid (Edema, 2011), hydroxy propyl methyl cellulose (De la Hera et al., 2013) to aid the final quality of maize bread. The use of additives increases the cost of the final wheat-free bread (reviewed by Moroni et al., 2009), a critical issue where consumers are food insecure. Sourdough fermentation seems to be a promising alternative to the use of additives since it is a natural and inexpensive process (reviewed by Moroni et al., 2009). Sourdough is a mixture of flour and water that is fermented by naturally occurring lactic acid bacteria (LAB) and yeast (Hammes and Gänzle, 1998). Success has been reported in the use of sourdough fermentation on the improvement of the quality of wheat bread and some wheat-free breads (reviewed by Arendt et al., 2007; Edema et al., 2013). 
The positive effects of sourdough on the quality of wheat breads may be attributed to the direct influence of low pH on structure forming dough components such as gluten, starch and arabinoxylans (reviewed by Schober et al., 2003). Although maize does not contain gluten, gluten-like functionality of zein (maize prolamin) dough as a result of acidification with lactic acid and acetic acid has been reported (Sly et al., 2014). The lactic acid bacteria fermentation process also acts on the other major structural component in dough, namely starch (Petrofsky and Hoseney, 1995). Edema et al. (2013) attributed the improvement in fonio dough and bread brought about by the use of a sourdough to starch modification (slight granule swelling and probably some leaching of starch molecules) to the activities of endogenous amylases from the sourdough microorganism whose activities were favoured at low $\mathrm{pH}$. This present work will focus on how a sourdough fermentation process, which has proven to be effective in improving the quality of fonio bread (Edema et al., 2013), improves the quality of maize bread with particular attention to its effect on the rheological properties of maize dough.

\section{Experimental}

\subsection{Materials}

Refined maize meal (Impala Special Maize Meal, Premier Foods, Isando, South Africa) with a protein content $8.6 \mathrm{~g} / 100 \mathrm{~g}(\mathrm{db})$ and a fat content $2.7 \mathrm{~g} / 100 \mathrm{~g}(\mathrm{db})$ was milled into a flour using a laboratory hammer grinder (Mikro-Feinmuhle-Culatti MFC grinder, Janke and Kunkel, Staufen, Germany) fitted with a $0.5 \mathrm{~mm}$ opening screen. A Lactobacillus plantarum culture (B411) was obtained from the Council for Scientific and Industrial Research, Pretoria, South Africa. 


\subsection{Methods}

2.2.2 Preparation of the sourdoughs and chemically acidified dough

L. plantarum sourdough was prepared by mixing maize flour (75 g) with sterile distilled water $(75 \mathrm{ml})$ containing $L$. plantarum cells $\left(9.3 \times 10^{10} \mathrm{cfu} / \mathrm{ml}\right)$ in a ratio of $1: 1(\mathrm{w} / \mathrm{v})$. The mixture was fermented at $30^{\circ} \mathrm{C}$ to a $\mathrm{pH}$ range of 3.3-3.6 (approx. $24 \mathrm{~h}$ ). Multiple strains starter culture fermented maize sourdough was prepared by mixing maize flour (75 g) with sterile distilled water $(75 \mathrm{ml})$. The maize dough was left to ferment for $72-96 \mathrm{~h}$ at ambient temperature $\left(22^{\circ} \mathrm{C}\right)$. A portion of the fermented maize dough was used as a starter (backslopping) for a fresh mixture of maize flour and water. The mixture was fermented at $30^{\circ} \mathrm{C}$ to $\mathrm{pH}$ range of 3.4-3.7 (approx. $48 \mathrm{~h}$ ). The final cell count of the L. plantarum fermented maize sourdough and the multiple strains starter culture fermented maize dough ('wild' sourdough) was 6.4 x $1010 \mathrm{cfu} / \mathrm{g}$ and 8.6 x 10 10cfu/g respectively. Chemically acidified maize dough was prepared by adding $0.1 \%$ lactic acid to the mixture of maize flour and water to $\mathrm{pH} 3.4$.

\subsubsection{Maize bread making and quality analysis}

This was performed as described by Edema et al. (2013) with some modifications. The remaining baking ingredients per $100 \mathrm{~g}$ of flour were: sugar (10 g), salt (1.5 g), soft margarine (5 g) and instant dried yeast (2 g) and water ( $15 \mathrm{ml}$ ). These were added to the sourdoughs and the chemically acidified doughs and mixed together. First proofing was at $30^{\circ} \mathrm{C}$ for $20 \mathrm{~min}$. The maize bread dough was remixed and scooped into silicone pans $(70 \mathrm{~mm}$ top diam and $58 \mathrm{~mm}$ bottom diam) to half full (47 $\mathrm{g}$ dough). The second proof was at $30^{\circ} \mathrm{C}$ for 15 min. Baking was at $200^{\circ} \mathrm{C}$ for $20 \mathrm{~min}$. Bread volume was determined. Crumb structure was measured by scanning cut surfaces of the bread using a flatbed scanner. The number and size of cells was determined by using Image J software 1.42 q/ Java 1.6.0_10 (32-bit), Wayne Rasband, National Institutes of Health, Bethesda, Maryland. Bread firmness was determined 
by using a TA-XT2 texture analyser (Stable Micro Systems, Godalming, UK) with a $20 \mathrm{~mm}$ radius cylinder probe $(\mathrm{P} / 20 \mathrm{~L})$. Pre-Test speed was $1.0 \mathrm{~mm} / \mathrm{s}$, test speed $1.7 \mathrm{~mm} / \mathrm{s}$ to $40 \%$ strain.

\subsubsection{Stress relaxation of the maize dough treatments}

Stress relaxation was measured using a texture analyser (EZ-L, Shimadzu, Kyoto, Japan). A plastic rod (43 mm diam and $10 \mathrm{~mm}$ height) was used at a 25\% strain to compress the maize dough for $5 \mathrm{sec}$, after which the dough was allowed to relax over a period of $180 \mathrm{sec}$. Relaxation time was calculated as the time required for the maximum force of compression to drop to $36.8 \%$ of its value, as described by Singh et al. (2006).

\subsubsection{Maize dough rheology during baking}

Strain sweep analysis was performed using a Physica MCR 101 Rheometer with Rheoplus software (Anton Paar, Ostfildern, Germany) to determine the linear viscoelastic region of the maize dough treatments prior to the temperature sweep test. Parallel plate geometry with a 25 mm diam probe and $2 \mathrm{~mm}$ gap between the top and bottom plate was used. The strain measured ranged from 0.01 to100\% at constant frequency of $6.3 \mathrm{rad} / \mathrm{s}(1 \mathrm{~Hz})$ measured at $4^{\circ} \mathrm{C}$. Excess dough was removed with a spatula and paraffin oil was put at the edges of the dough to prevent it drying. Temperature sweep analysis was performed to estimate the changes that would occur in dough properties during baking. This analysis was done within the linear viscoelastic range $(0.1 \%)$ of the maize dough as determined earlier by strain sweep analysis. Frequency was kept constant at $6.3 \mathrm{rad} / \mathrm{s}(1 \mathrm{~Hz})$ and the temperature range was from $25-150^{\circ} \mathrm{C}$ for $20 \mathrm{~min}$ at a heating rate of $6.25^{\circ} \mathrm{C} / \mathrm{min}$. Excess dough was scraped off but no paraffin oil was added to the edges because it caused a bubbling effect at higher temperatures. 
2.2.6 Structural properties of the maize dough treatments and maize bread Confocal laser scanning microscopy (CLSM) (Zeiss 510 META system, Jena, Germany) with a Plan-Neofluar $10 \times 0.3$ objective under natural fluorescence at an excitation wavelength of $405 \mathrm{~nm}$ was used. Dough ( $<1 \mathrm{~g})$ or maize bread (1mm thick slice) was attached to a slide with double sided tape. Samples were stained with 0.5\% acid magneta dye (Maeda et al., 2013). The stained samples were dried in an oven at $60^{\circ} \mathrm{C}$ for $1 \mathrm{~min}$. Dried samples were mounted on the stage of the CLSM and viewed. Images were captured using a micro- and macro-photography ultra-high resolution digital camera.

\subsubsection{Thermal properties of the maize doughs}

These were determined by Differential Scanning Calorimetry (DSC) with STARe software (HPDSC-827, Mettler Toledo, Schwerzenbach, Switzerland). Maize dough treatments were prepared as for baking but without yeast. Maize dough (45-50 mg) was weighed into a $100 \mu \mathrm{l}$ aluminium DSC pan. Scanning was from 30 to $120^{\circ} \mathrm{C}$ at a rate of $10^{\circ} \mathrm{C} / \mathrm{min}$. Nitrogen, at normal air pressure and $50 \mathrm{ml} / \mathrm{min}$ flow rate was used. Onset $\left(\mathrm{T}_{\mathrm{o}}\right)$, peak $\left(\mathrm{T}_{\mathrm{p}}\right)$, conclusion gelatinization $\left(\mathrm{T}_{\mathrm{c}}\right)$ temperatures were measured and enthalpy $(\Delta \mathrm{H})$ was calculated.

\subsection{Statistical analyses}

All experiments were performed at least twice. Results were analysed using one-way analysis of variance (ANOVA). Fisher’s Least Significant Difference Test (LSD) was used to determine significant differences between the treatments at $\mathrm{p}=0.05$.

\section{Results and discussion}

\subsection{Maize bread quality}

Loaf height, loaf volumes and specific volume of maize breads made with sourdoughs: $L$. plantarum fermented maize sourdough or multiple strains starter culture fermented maize sourdough were significantly $(\mathrm{p}<0.05$ ) higher (by 25-26\%) than maize bread made from 
L. plantarum fermented maize sourdough bread
Multiple strains starter culture fermented maize sourdough bread
Chemically acidified

maize bread

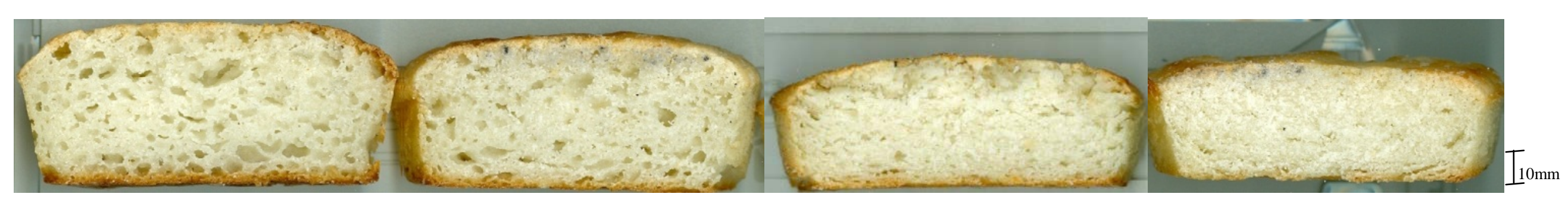

Fig 1: Effects of L. plantarum or multiple strains starter culture fermented maize sourdough on the crumb structure of maize bread 
Table 1: Effects of L. plantarum fermentation or multiple strains starter culture fermentation on the quality of maize bread (loaf volume, force required to compress the maize bread, number and size of the cells)

\begin{tabular}{|c|c|c|c|c|c|c|c|}
\hline Treatments & $\begin{array}{l}\text { Weight after } \\
\text { baking } \\
\text { (g) } \\
\end{array}$ & $\begin{array}{l}\text { Height after } \\
\text { baking } \\
(\mathrm{mm}) \\
\end{array}$ & $\begin{array}{l}\text { Force required } \\
\text { to compress } \\
\text { maize bread } \\
(\mathrm{N}) \\
\end{array}$ & $\begin{array}{l}\text { Loaf volume } \\
\text { after baking } \\
\left(\mathrm{cm}^{3}\right)\end{array}$ & $\begin{array}{l}\text { Loaf specific } \\
\text { volume after } \\
\text { baking } \\
\left(\mathrm{cm}^{3} / \mathrm{g}\right) \\
\end{array}$ & $\begin{array}{l}\text { Number of } \\
\text { cells per } \\
\mathrm{mm}^{2}\end{array}$ & $\begin{array}{l}\text { Average diameter } \\
\text { of cells } \\
\qquad(\mathrm{mm})\end{array}$ \\
\hline Maize bread & $36.3^{\mathrm{b}} \pm 0.4^{1}$ & $21.0^{\mathrm{a}} \pm 0.0$ & $38.7^{c} \pm 3.5$ & $68.2^{\mathrm{a}} \pm 0.0$ & $1.9^{\mathrm{a}} \pm 0.0$ & ND & ND \\
\hline $\begin{array}{l}\text { Chemically acidified } \\
\text { maize bread }\end{array}$ & $35.2^{a} \pm 0.2$ & $20.5^{a} \pm 0.6$ & $15.6^{\mathrm{a}} \pm 3.1$ & $66.6^{\mathrm{a}} \pm 1.9$ & $1.9^{a} \pm 0.1$ & ND & ND \\
\hline $\begin{array}{l}\text { L. plantarum fermented } \\
\text { maize sourdough bread }\end{array}$ & $36.2^{b} \pm 0.2$ & $26.3^{b} \pm 1.3$ & $24.9^{b} \pm 0.3$ & $85.2^{b} \pm 4.1$ & $2.3^{b} \pm 0.1$ & $109.0^{a} \pm 5.7$ & $1.9^{\mathrm{a}} \pm 0.2$ \\
\hline $\begin{array}{l}\text { Multiple strains starter } \\
\text { culture fermented } \\
\text { maize sourdough bread }\end{array}$ & $35.8^{\mathrm{ab}} \pm 0.2$ & $26.5^{b} \pm 1.0$ & $27.7^{b} \pm 2.0$ & $86.0^{b} \pm 3.3$ & $2.4^{\mathrm{b}} \pm 0.1$ & $112.0^{\mathrm{a}} \pm 14.1$ & $12.0^{a} \pm 0.3$ \\
\hline
\end{tabular}

${ }^{1}$ Means and standard deviation $\mathrm{n}=2$. Values followed by different letters in the same column are significantly different at $\mathrm{p}<0.05$. ND: not detectable 
chemically acidified maize dough or maize dough without sourdough or chemical acidification (straight maize dough) (Table 1, Fig. 1). The maize sourdough breads had a more open crumb structure with discrete gas, whereas a compact crumb structure (Fig 1) with ruptured cells (Fig. 2A) was observed in the maize breads made by the straight dough process or with chemical acidification. Less force was also required to compress the maize sourdough breads than required for the maize bread without sourdough (Table 1). The chemically acidified maize bread required the least amount of force to compress the bread. However, it crumbled more easily than the other maize breads (Fig. 2A).

As chemical acidification did not improve the quality of maize bread, this suggests that the effect of the sourdough was much more than simple reduction in pH. Clarke et al. (2002) and Dal Bello et al. (2007) both worked on effects of wheat sourdough on wheat bread quality. These authors also reported that biological acidification of wheat dough with sourdough yielded breads with greater specific loaf volumes when compared to either the non-acidified or the chemically acidified treatments. Clarke et al. (2002) hypothesized that, due to the addition of sourdough, some physicochemical changes in protein network occurred. They further explained that this changes may have facilitated a greater expansion of the sourdough bread during proofing due to the softer and more extensible nature of the dough.

Edema et al. (2013) who worked on improvement of fonio dough properties through starch modification by sourdough fermentation and Schober et al. (2007) whose study was conducted to improve the quality and theoretical understanding of gluten-free sorghum bread, both also found that sourdough fermentation improved the quality of fonio and sorghum breads, respectively. The improvement in maize bread quality may be due to dough modification. Edema et al. (2013) attributed the improvement in fonio bread quality brought 


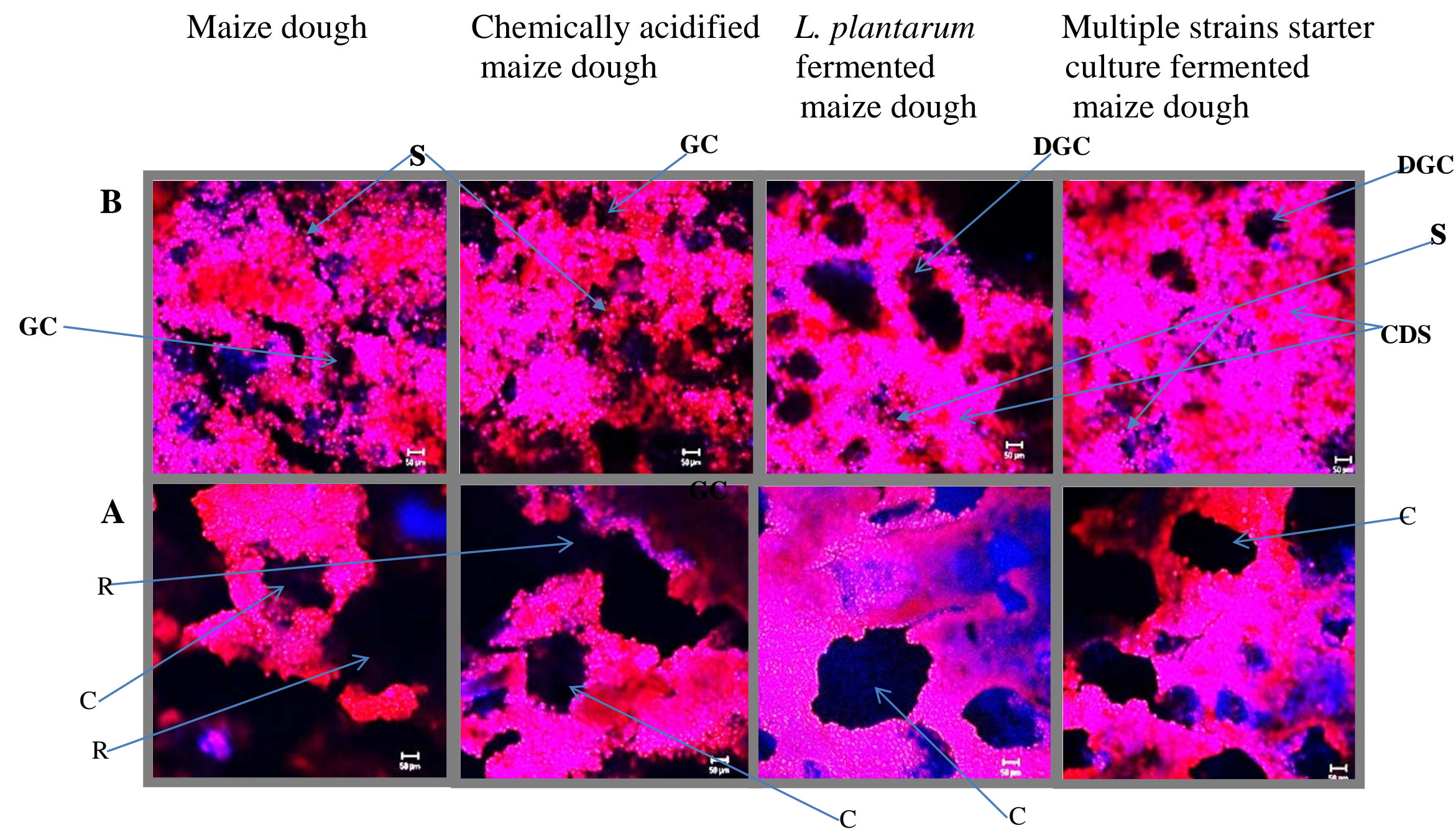

A: Maize bread, B: Maize dough, GC: gas cell, DGC: defined gas cell, C: cell, R: rupture, CDS: cohesive dough structure, S: starch granule

Fig 2: Confocal laser scanning microscopy showing the effects of $L$. plantarum fermentation or multiple strains starter culture fermentation on the microstructure of maize bread and maize dough 
about by sourdough fermentation specifically to starch modification (slight granule swelling and probably some leaching of starch molecules) by endogenous amylases from the sourdough microorganism whose activities were favoured at low pH. Schober et al. (2007) also attributed the improvement in sorghum bread to dough modification. These authors concluded that the major effect of sourdough fermentation was the degradation of proteins soluble in the dough liquid. These authors further proposed that if these proteins were not degraded, they would aggregate upon baking and interfere with the starch gel. As a result, sorghum bread without sourdough fermentation tended to have a large hole in the crumb.

To determine how sourdough fermentation improves maize bread quality, the rheological, thermal and structural properties of the sourdoughs were examined.

\subsection{Stress relaxation of maize dough}

The sourdoughs required a lower amount to force to compress to $25 \%$ strain (Fig 3). They also required a shorter relaxation time [the time required for the maximum force of compression to drop to $36.8 \%$ of its value (Singh et al., 2006)] than the chemically acidified maize dough or the straight maize dough. The lower amount of force required and shorter relaxation time required by maize sourdoughs compared to that required by the chemically acidified maize dough and straight dough indicates that the sourdoughs were softer, and less elastic. Keentok et al. (2002) associated strong wheat flours with longer relaxation times and weak flours with shorter relaxation times. The terms strong and weak when used to describe wheat flour refers to the quality of the gluten for gluten bread manufacture (Tipples et al., 1994). However, this may not be the case for maize gluten-free dough. 


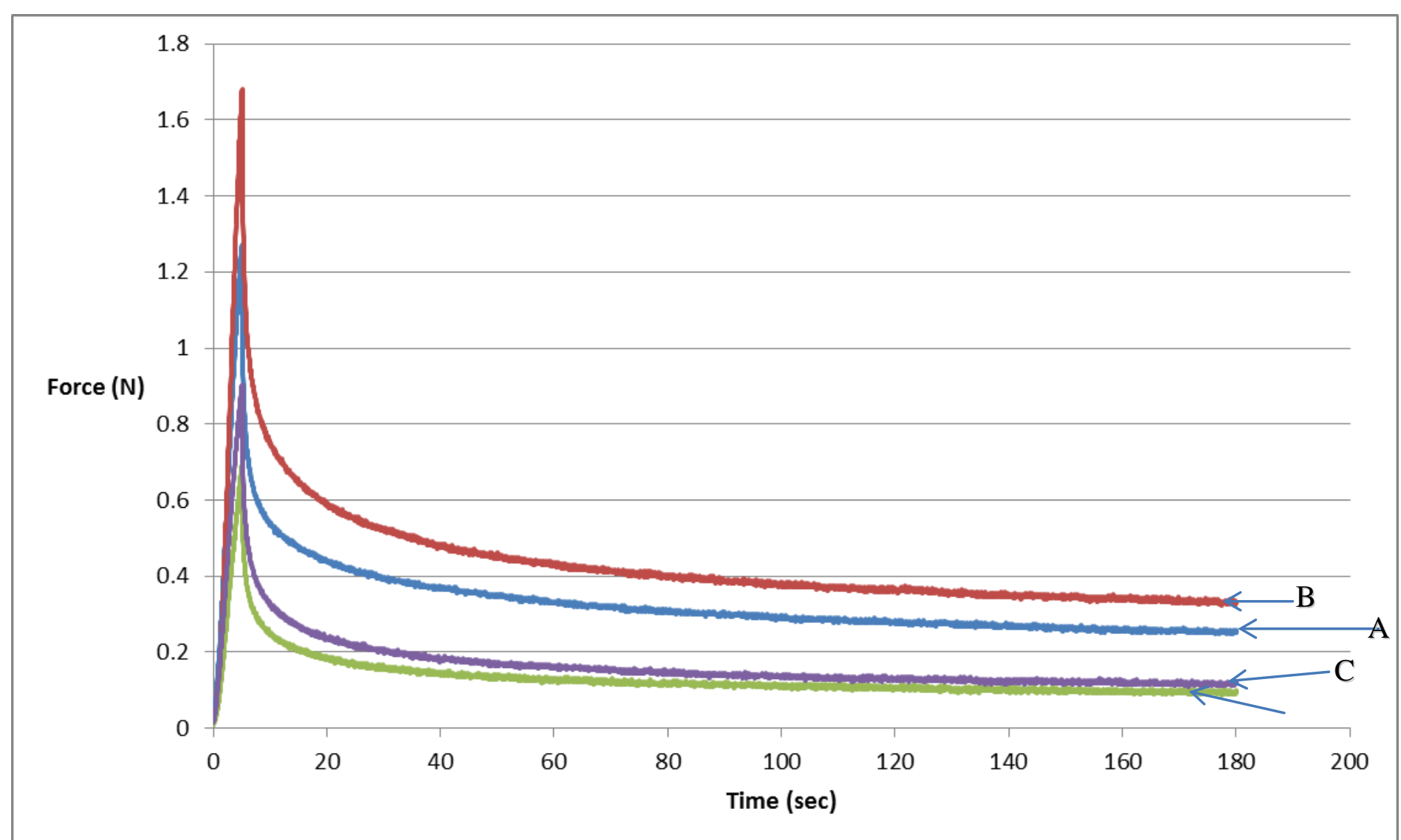

a: maize dough. b: chemically acidified maize dough. c: L. plantarum fermented maize dough. d: multiple strains starter culture fermented maize dough

Fig 3: Effects of L. plantarum or multiple strains starter culture fermentation on stress relaxation of maize dough 


\subsection{Dough rheology under simulated baking conditions}

With strain sweep analysis, none of the treatments had a significant effect on the linear viscoelastic region of the maize doughs (Fig 4A I and II). However, all the treatments showed a higher elastic modulus $\left(\mathrm{G}^{\prime}\right)$ than the loss modulus $\left(\mathrm{G}^{\prime \prime}\right)$. Concerning the temperature sweep analysis, though the elastic modulus $\left(G^{\prime}\right)$ and complex viscosity $\left(\eta^{*}\right)$ curves of all the treatments initially diminished in the same pattern (from $25^{\circ} \mathrm{C}$ to about $75^{\circ} \mathrm{C}$ ), the maize sourdoughs had lower $\mathrm{G}^{\prime}$ and $\eta^{*}$ than the chemically acidified and straight doughs (Fig 4B IV and V). As the temperature increased to $85^{\circ} \mathrm{C}$ through to $95^{\circ} \mathrm{C}, \mathrm{G}^{\prime}$ and $\eta^{*}$ of all the treatments became similar. At around $90^{\circ} \mathrm{C}, \mathrm{G}^{\prime}$ and $\eta^{*}$ of all the treatments started to decrease with $L$. plantarum maize sourdough having the lowest values at around $130^{\circ} \mathrm{C}$. At around $140-150^{\circ} \mathrm{C}$, maize sourdoughs showed lower $G^{\prime}$ and $\eta^{*}$. Maize sourdoughs also had higher $\tan \delta$ at the beginning of the analysis. According to Stathopoulos et al. (2008), a higher tan $\delta$ indicates a greater degree of viscous behaviour (less elastic) while a lower $\tan \delta$ indicates more elastic behaviour. At around $65-75^{\circ} \mathrm{C}$, maize sourdoughs showed a considerable increase in $\tan \delta$ compared to that observed in the chemically acidified and straight doughs. However, all the treatments showed similar $\tan \delta$ around $85-90^{\circ} \mathrm{C}$. At $149-150^{\circ} \mathrm{C}$, $\tan \delta$ of maize sourdoughs started to decrease, while that of the chemically and straight doughs started to increase.

Moroni et al. (2011) who investigated the impact of sourdough on buckwheat flour, batter and bread, also found higher elastic modulus than viscous modulus. Clarke et al. (2002), and Angioloni et al. (2006) who worked on the influence of sourdough fermentation on the fundamental rheological properties of wheat dough also found that the addition of sourdough led to a less elastic bread dough.

The higher elastic modulus than viscous modulus exhibited by all the maize doughs suggests that the doughs are viscoelastic solids, exhibiting more elastic properties than viscous properties. That maize sourdoughs had lower elastic modulus, loss modulus, and required a 
I

A

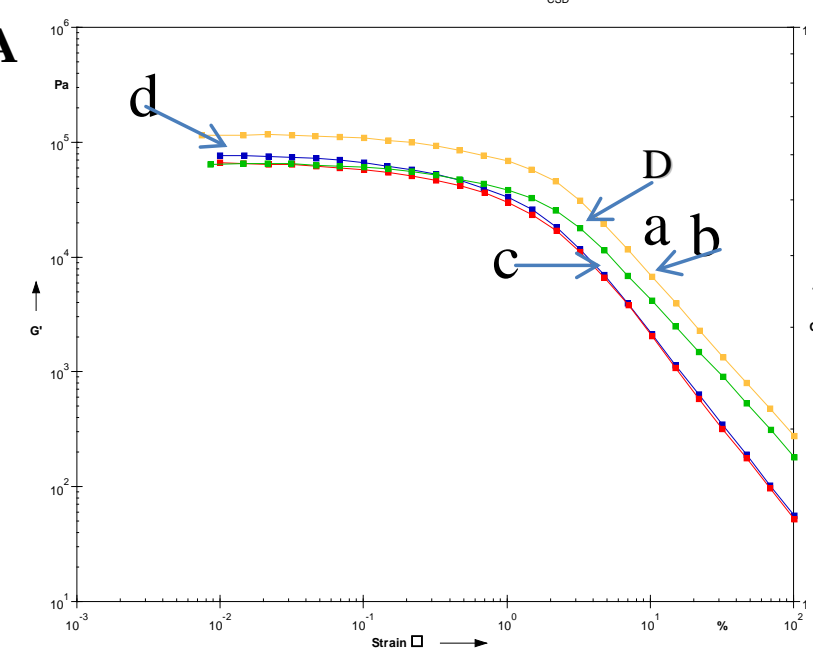

IV

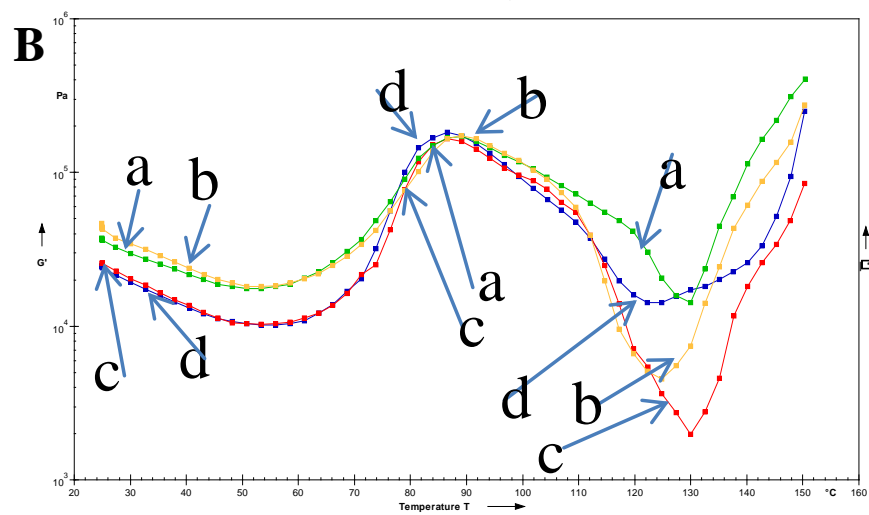

II

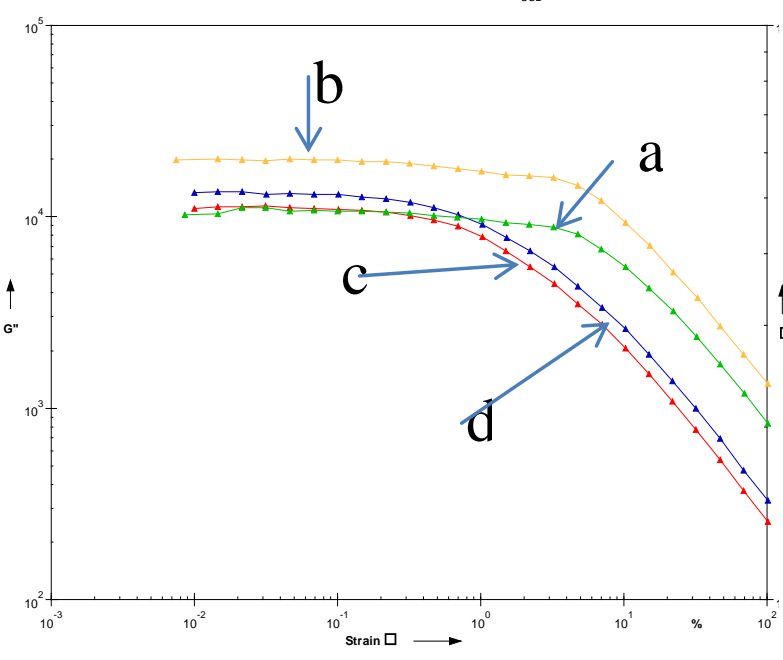

V
III

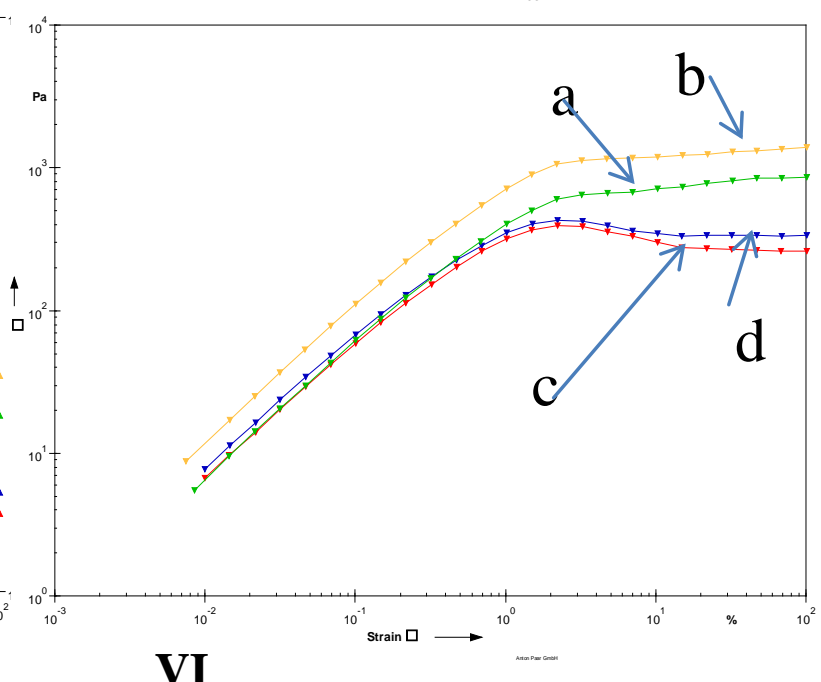

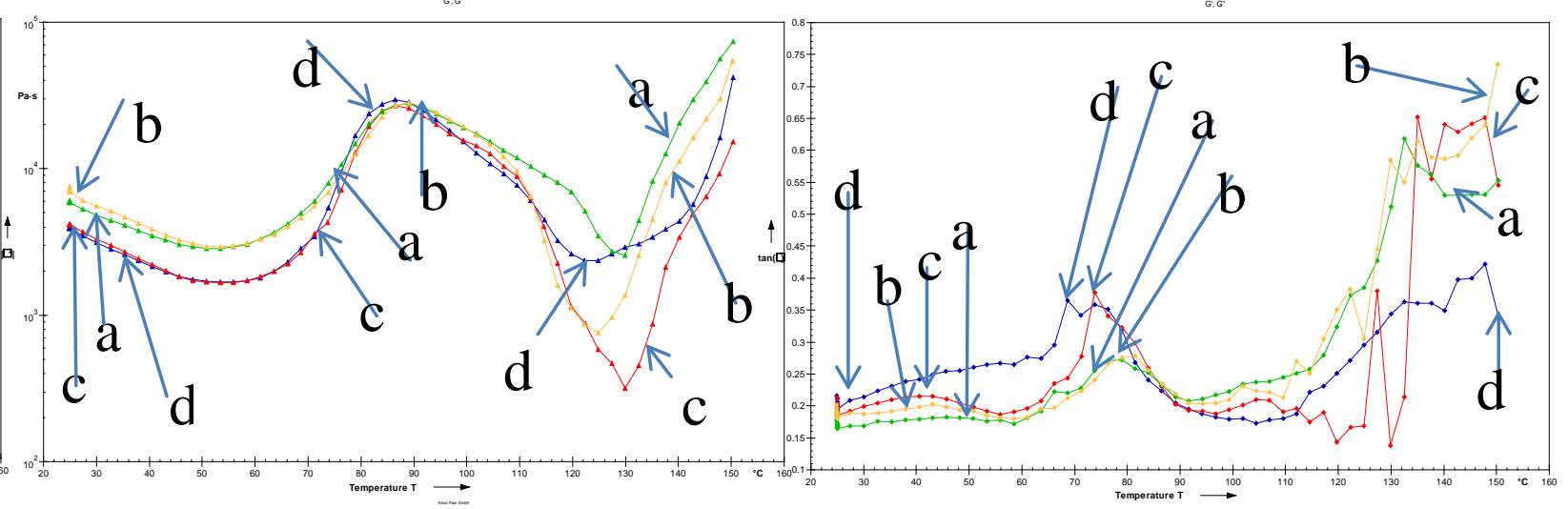

a: maize dough. b: chemically acidified maize dough. c: L. plantarum fermented maize dough. d: multiple strains starter culture fermented maize dough

Fig 4: Effects of L. plantarum fermentation or multiple strains starter culture fermentation on the rheological properties of maize dough. A: strain sweep analysis parameters within a strain of 0.01-100\% (I: elastic modulus and linear viscoelastic region, II: loss modulus, III: shear stress), B: temperature sweep analysis parameters within a temperature range of $25-150^{\circ} \mathrm{C}$ (IV: elastic modulus, V: complex viscosity, V?.? ?an $^{3}$ ) 
lower shear stress than the chemically acidified and straight doughs also indicates that the sourdoughs had softer or less elastic dough. This suggests that sourdough fermentation had an effect on the elasticity of maize dough which was not brought about by chemical acidification. According to Hammes and Gänzle, (1998) and Thiele et al. (2002), sourdough fermentation process does much more to influence the properties of the dough than simply produce acid. Clarke et al. (2002) assumed that the time frame during which enzyme activity could affect the dough constituents was shorter for chemically acidified dough compared to the biologically acidified doughs. They explained that the changing $\mathrm{pH}$ values during sourdough fermentation period may also afford passage through a range of $\mathrm{pH}$ values close to the optimum for various enzymes present in the dough system. Thus, they suggested that the activity of the protease and amylase enzymes present may be influenced to a greater extent by the $\mathrm{pH}$ profile of the biological acidification fermentation period in contrast to the almost instant nature of the chemically acidified time frame. The decrease in $\tan \delta$ of maize sourdoughs at the end of the temperature sweep analysis may not necessarily mean that they were harder, it may simply imply that at the end of baking, the maize sourdough breads become strong enough to resist rupturing (Fig. 2A). However, this was not the case for chemically acidified or straight dough maize bread which easily ruptured.

\subsection{Dough thermal properties}

Maize sourdoughs had a slightly lower peak endotherm than chemically acidified or straight maize doughs (Table 2). Maize sourdoughs also had a higher enthalpy for the endothermic peak, indicating a higher energy requirement to disrupt the starch granules. León et al. (1997) working on starch changes occurring in wheat bread baking and storage, and Sanz-Penella et al. (2012) working on developing whole wheat bread with increased nutritional quality using 
Table 2: Effects of L. plantarum fermentation or multiple strains starter culture fermentation on the thermal properties of maize dough using the Differential Scanning Calorimetry

\begin{tabular}{lcccc}
\hline Treatments & $\begin{array}{c}\text { Onset } \\
\text { temperature } \\
\left({ }^{\circ} \mathrm{C}\right)\end{array}$ & $\begin{array}{c}\text { Peak } \\
\text { temperature } \\
\left({ }^{\circ} \mathrm{C}\right)\end{array}$ & $\begin{array}{c}\text { Endset } \\
\text { temperature } \\
\left({ }^{\circ} \mathrm{C}\right)\end{array}$ & $\begin{array}{c}\text { Enthalpy } \\
(\Delta \mathrm{H}) \\
(\mathrm{J} / \mathrm{g})\end{array}$ \\
\hline $\begin{array}{l}73.43^{\mathrm{a}} \pm 0.04 \\
\text { Maize dough }\end{array}$ & $73.83^{\mathrm{a}} \pm 0.05$ & $82.09^{\mathrm{bc}} \pm 0.42$ & $88.68^{\mathrm{a}} \pm 0.04$ & $0.38^{\mathrm{a}} \pm 0.02$ \\
$\begin{array}{l}\text { Chemically acidified } \\
\text { maize dough }\end{array}$ & $72.87^{\mathrm{a}} \pm 1.94$ & $79.81^{\mathrm{b}} \pm 0.37$ & $89.84^{\mathrm{a}} \pm 0.07$ & $0.49^{\mathrm{a}} \pm 0.00$ \\
$\begin{array}{l}\text { L. plantarum fermented } \\
\text { maize sourdough }\end{array}$ & & & $89.84^{\mathrm{a}} \pm 0.93$ & $1.06^{\mathrm{b}} \pm 0.28$ \\
$\begin{array}{l}\text { Multiple strains starter } \\
\text { culture fermented maize } \\
\text { sourdough }\end{array}$ & $71.39^{\mathrm{a}} \pm 0.38$ & $77.28^{\mathrm{a}} \pm 0.82$ & $88.13^{\mathrm{a}} \pm 3.74$ & $1.13^{\mathrm{b}} \pm 0.19$ \\
\end{tabular}

${ }^{1}$ Means and standard deviation $\mathrm{n}=2$. Values in the same column followed by different letters are significantly different at $\mathrm{p}<0.05$ 
sourdough, both reported that the gelatinization enthalpy of fermented doughs were higher than that of the unfermented doughs.

The changes observed in the thermal properties of the doughs brought about by sourdough fermentation also indicate some starch modification. According to Murphy (2000), acid predominantly depolymerises the amorphous regions of the starch granule such that when the starch is heated beyond its gelatinisation temperature, starch granules rupture quickly. If the amorphous region is depolymerised, only the crystalline region is left, therefore, more energy will be required to depolymerise this region. Also, acidification increases the water binding capacity of starch granules (Hammes and Gänzle, 1998). This suggests that lactic acid produced by lactic acid bacteria during sourdough fermentation of maize dough had an effect on the glycosidic bonds in the starch granule, hydrolysing them and enabling the starch granules to absorb water faster. However, since the chemical acidification did not produce the same effect, part of the effect of the lactic acid fermentation was probably due to the activities of endogenous enzymes in the sourdough microorganisms favoured by the low $\mathrm{pH}$, as reported by Edema et al. (2013). These authors explained starch modification as slight changes in the starch granules, which probably increased water absorption. Similarly, León et al. (1997) and Sanz-Penella et al. (2012) attributed the higher gelatinization enthalpy required by the sourdoughs to be due to better starch hydration during the period of fermentation.

\subsection{Dough structural properties}

When viewed by CLSM, all the maize doughs showed the presence of gas cells (Fig. 2B). However, the gas cells were more distinct in the maize sourdoughs. The sourdoughs also showed a cohesive (a complete and continuous matrix) dough structure compared to the chemically acidified or straight doughs which showed more grainy dough structure. Also, few 
individual starch granules were visible in the sourdoughs, whereas many discrete starch granules were visible in the chemically acidified and straight doughs.

The presence of more distinct gas cells in the sourdoughs is indicative of dough modification improving the dough's ability to withstand the pressure of the expanding $\mathrm{CO}_{2}$ in the gas cells without collapsing. According to Edema et al. (2013), sourdough fermentation improves fonio dough by increasing the water absorption capacity of the dough. This in-turn improved dough strength and gas holding capacity of the dough.

The cohesive dough structure observed in the sourdough breads may be related to endosperm matrix protein degradation as explained by Schober et al. (2007). Degradation of the protein possibly enabled the partial starch hydrolysis and also leaching of amylose. The leached amylose would be capable of forming a network (Goesaert et al., 2005), which probably resulted in the formation of a cohesive dough structure, as observed.

\section{Conclusions}

Sourdough fermentation of maize dough substantially increases loaf volume and results in a more open crumb structure of the bread. Sourdough fermented maize dough is softer and less elastic, but less crumbly than chemically acidified maize dough or straight maize dough. It appears that the improvement in maize bread quality is due to starch granule modification, which although it makes the dough less elastic, improves its ability to trap carbon dioxide and withstand the pressure of the expanding gas in the dough. It may be proposed that softer cohesive dough is the key to make good gluten-free maize bread without the use of additives. 


\section{Acknowledgement}

A.T. Falade thanks the University of Pretoria for an Institutional Research Theme Bursary.

\section{References}

Angioloni, A., Romani, S., Pinnavaia, G.G., Dalla Rosa, M., 2006. Characteristics of bread making doughs: influence of sourdough fermentation on the fundamental rheological properties. European Food Research and Technology 222, 54-57.

Arendt, E.K., Ryan, L.A., Dal Bello, F., 2007. Impact of sourdough on the texture of bread. Food Microbiology 24, 165-174.

Brites, C., Trigo, M.J., Santos, C., Collar, C., Rosell, C.M., 2010. Maize-based gluten-free bread: influence of processing parameters on sensory and instrumental quality. Food and Bioprocess Technology 3, 707-715.

Clarke, C., Schober, T., Arendt, E., 2002. Effect of single strain and traditional mixed strain starter cultures on rheological properties of wheat dough and on bread quality. Cereal Chemistry 79, 640-647.

Dal Bello, F., Clarke, C., Ryan, L., Ulmer, H., Schober, T., Ström, K., Sjögren, J., Van Sinderen, D., Schnürer, J., Arendt, E., 2007. Improvement of the quality and shelf life of wheat bread by fermentation with the antifungal strain Lactobacillus plantarum. Journal of Cereal Science 45, 309-318. 
De la Hera, E., Talegón, M., Caballero, P., Gómez, M., 2013. Influence of maize flour particle size on gluten-free breadmaking. Journal of the Science of Food and Agriculture 93, 924-932.

Edema, M.O., 2011. A modified sourdough procedure for non-wheat bread from maize meal. Food and Bioprocess Technology 4, 1264-1272.

Edema, M.O., Emmambux, M.N., Taylor, J.R.N., 2013. Improvement of fonio dough properties through starch modification by sourdough fermentation. Starch/Stärke 65, 730737.

FAOSTAT. 2012. Cereal production in Africa. Accessed online at http://faostat.fao.org, March, 2014.

Goesaert, H., Brijs, K., Veraverbeke, W., Courtin, C., Gebruers, K., Delcour, J., 2005. Wheat flour constituents: how they impact bread quality, and how to impact their functionality. Trends in Food Science \& Technology 16, 12-30.

Goodall, M.A., Campanella, O.H., Ejeta, G., Hamaker, B.R., 2012. Grain of high digestible, high lysine (HDHL) sorghum contains kafirins which enhance the protein network of composite dough and bread. Journal of Cereal Science 56, 352-357.

Hammes, W.P., Gänzle, M.G., 1998. Sourdough breads and related products. In: Woods, B.J.B. ( $2^{\text {nd }}$ Ed.), Microbiology of fermented foods, vol. 1. Blackie Academic and Professional, London, UK, pp. 199-216.

Keentok, M., Newberry, M.P., Gras, P., Bekes, F., Tanner, R.I., 2002. The rheology of bread dough made from four commercial flours. Rheologica Acta 41, 173-179. 
León, A., Durán, E., de Barber, C.B., 1997. A new approach to study starch changes occurring in the dough-baking process and during bread storage. Zeitschrift für Lebensmitteluntersuchung und-Forschung A 204, 316-320.

Maeda, T., Kokawa, M., Miura, M., Araki, T., Yamada, M., Takeya, K., Sagara, Y., 2013. Development of a novel staining procedure for visualizing the gluten-starch matrix in bread dough and cereal products. Cereal Chemistry 90, 175-180.

Mejia, C.D., Gonzalez, D.C., Mauer, L.J., Campanella, O.H., Hamaker, B.R., 2012. Increasing and stabilizing $\beta$-sheet structure of maize zein causes improvement in its rheological properties. Journal of Agricultural and Food Chemistry 60, 2316-2321.

Moroni, A.V., Bello, F.D., Zannini, E., Arendt, E.K., 2011. Impact of sourdough on buckwheat flour, batter and bread: biochemical, rheological and textural insights. Journal of Cereal Science 54, 195-202.

Moroni, A.V., Dal Bello, F., Arendt, E.K., 2009. Sourdough in gluten-free bread-making: an ancient technology to solve a novel issue? Food Microbiology 26, 676-684.

Murphy, P., 2000. Starch. In: Phillips, G. O., Williams, P. A. (Ed.), Handbook of hydrocolloids. CRC Press, Boca Raton, FL, pp. 41-65.

Petrofsky, K., Hoseney, R., 1995. Rheological properties of dough made with starch and gluten from several cereal sources. Cereal Chemistry 72, 53-57.

Sanni, A., Onilude, A., Fatungase, M., 1997. Production of sour maize bread using startercultures. World Journal of Microbiology and Biotechnology 14, 101-106. 
Sanz-Penella, J.M., Tamayo-Ramos, J.A., Haros, M., 2012. Application of bifidobacteria as starter culture in whole wheat sourdough breadmaking. Food and Bioprocess Technology 5, 2370-2380.

Schober, T.J., Bean, S.R., Boyle, D.L., 2007. Gluten-free sorghum bread improved by sourdough fermentation: biochemical, rheological, and microstructural background. Journal of Agricultural and Food Chemistry 55, 5137-5146.

Schober, T.J., Dockery, P., Arendt, E.K., 2003. Model studies for wheat sourdough systems using gluten, lactate buffer and sodium chloride. European Food Research and Technology 217, 235-243.

Singh, H., Rockall, A., Martin, C., Chung, O., Lookhart, G., 2006. The analysis of stress relaxation data of some viscoelastic foods using a texture analyzer. Journal of Texture Studies 37, 383-392.

Sly, A.C., Taylor, J., Taylor, J.R.N., 2014. Improvement of zein dough characteristics using dilute organic acids. Journal of Cereal Science.

http://0-dx.doi.org.innopac.up.ac.za/10.1016/j.jcs.2014.02.006

Stathopoulos, C.E., Tsiami, A.A., David Schofield, J., Dobraszczyk, B.J., 2008. Effect of heat on rheology, surface hydrophobicity and molecular weight distribution of glutens extracted from flours with different bread-making quality. Journal of Cereal Science 47, 134-143.

Thiele, C., Gänzle, M., Vogel, R., 2002. Contribution of sourdough lactobacilli, yeast, and cereal enzymes to the generation of amino acids in dough relevant for bread flavor. Cereal Chemistry 79, 45-51. 
Tipples, K., Kilborn, R., Preston, K., 1994. Bread-wheat quality defined. In: Bushuk, W., Rasper, V.F. (Ed.), Wheat: production, properties and quality. Blackie Academic and Professional, London, UK, pp. 25-35. 